ORIGINAL ARTICLE

\title{
Colorectal Anastomosis Leak: Rate, Risk Factors and Outcome in a Tertiary Teaching Hospital, Addis Ababa Ethiopia, a Five Year Retrospective Study
}

\author{
Gutema Wako ${ }^{1}$, Henok Teshome ${ }^{2}$, Engida Abebe ${ }^{3}$
}

OPEN ACCESS

Citation: Gutema Wako, Henok Teshome, Engida Abebe. Colorectal Anastomosis Leak: Rate, Risk Factors and Outcome in a Tertiary Teaching Hospital, Addis Ababa Ethiopia, Five Year Retrospective Study. Ethiop J $\begin{array}{lll}\text { Health Sci. 2019;29(6):767. } & \text {. }\end{array}$ doi:http://dx.doi.org/10.4314/ejhs.v29

i6.14

Received: July 14, 2018

Accepted: August 26, 2019

Published: November 1, 2019

Copyright: (2019 Gutema Wako, Henok Teshome, Engida Abebe.. This is an open access article distributed under the terms of the Creative Commons Attribution License, which permits unrestricted use, distribution, and reproduction in any medium, provided the original author and source are credited.

Funding:St. Paul's Hospital Millennium Medical College

Competing Interests: The authors declare that this manuscript was approved by all authors in its form and that no competing interest exists.

Affiliation and Correspondence:

${ }^{1}$ General Surgeon at Dodola Hospital

${ }^{2}$ Assistant Professor of Surgery, St.

Paul's Hospital Millennium Medical

College (SPHMMC) - Correspondent

${ }^{3}$ Associate Professor of Surgery, (SPHMMC)

*Email: hennyteshe@yahoo.com

\begin{abstract}
BACKGROUND: Anastomotic leakage is a morbid and potentially fatal complication of colorectal surgery. Determination of perioperative risk factors for colorectal anastomosis leak helps to identify patients requiring increased postoperative surveillance.

METHODS: Institution based retrospective study was done to determine colorectal anastomosis leak rate and risk factors associated with it at a teaching hospital in Addis Ababa Ethiopia. Patients operated from January 2013 to December 2017 G.C were included. Univariate analysis followed by a multivariate logistic regression model was used to determine the influence of patient factors and operative events on postoperative anastomotic leakage. RESULTS: Inclusion criteria were met by 221 patients. Mean age of patients was 46.44(SD=19.1) with range of 1 to 85 years. Male accounted to 166 (74.8\%) of the patients. Anastomotic leakage occurred in $12(5.2 \%)$ of the patients. Mean time to diagnosis was 9.55 days (95\% CI, 7.2-11.8) after surgery. Univariate analyses showed high preoperative level of creatinine, ASA score III and IV, emergency operation, operative time more than three hours, and malignant diseases were associated with colorectal anastomosis leak. Multivariate logistic regression model failed to show an association. Colorectal anastomosis leak increased the inpatient mortality rate by $50 \%$. Median length of hospitalization in colorectal anastomosis leak group was 27.5 days, versus 7 days in patients without leak.

CONCLUSION: Colorectal anastomosis leak remains common problem after colorectal surgery resulting significant post-operative mortality and morbidity.
\end{abstract}

Key words: Anastomosis, Anastomosis Leak, Risk factors

\section{INTRODUCTION}

Colorectal anastomosis is performed for several conditions of the colon; colorectal cancer, redundant sigmoid, trauma to the colon and rectum, colostomy reversal etc. When it occurs, anastomotic leakage (AL) after colorectal surgery is a dreadful complication leading to significant morbidity and mortality, not to mention longer hospital stay and significantly increased cost of care (1). Reported rates of 
anastomotic leakage vary widely (2.6\% and 19\%) depending on definition, site and type of anastomosis and the cohort under investigation. Mortality rates due to AL vary between $10 \%$ and $20 \% 9$ (2-6). Several studies have identified risk factors for $\mathrm{AL}$; however, there is no universal agreement on which risk factors consistently feature (7-11).

Widely accepted definition of anastomosis leak (AL) is lacking. An attempt to address this was made in 2010 by the International Study Group of Rectal Cancer (ISREC), based on exhaustive synthesis of Current literature. ISREC defined $\mathrm{AL}$ as 'a communication between the intra- and extra-luminal compartments owing to a defect of the integrity of the intestinal wall at the anastomotic site. In addition, a pelvic abscess adjacent to an anastomosis, even if no communication with the bowel lumen could be demonstrated, was considered to have originated from a leak. Recommendation was made for a simple grading system, based on clinical management, as follows: Grade A, resulting in no change in management; Grade $B$, requiring active therapeutic intervention but manageable without re laparotomy; and Grade $\mathrm{C}$, requiring relapratomy $(1,2)$.

Anastomotic defect causes leakage of colonic content into the abdominal and/or pelvic space leading to peritonitis, abscess formation and sepsis that can be fatal. The diagnostic methods commonly used when a leakage is suspected are CT scan, contrast enema, endoscopic examination, and reoperation. Anastomotic leakage typically becomes clinically apparent between the $5^{\text {th }}$ and $8^{\text {th }}$ postoperative day but many exceptions exist (5). Definition of clinically apparent anastomotic leakage is: 1) fecal fistula to skin or vagina 2) Fever more than 38 degree centigrade or septicemia 3) Radiological or Endoscopic signs of anastomotic leakage 4) Intra-peritoneal abscess or peritonitis in the presence of an anastomotic leak. Local data showing incidence of anastomotic leakage and its impact on clinical outcome is not available. As colorectal surgery is among the common surgeries practiced in our hospital the $\mathrm{AL}$ is expected to be there. To the best of our knowledge there is no study done in Ethiopia on burden and risk factors for AL. The benefits of identifying patients at high risk of anastomotic leakage provide the opportunity for better informed preoperative patient counseling and the potential for treatments to be tailoring. The objective of this study was to determine the rate, risk factors and outcome of clinically significant anastomotic leak after colorectal surgery.

\section{MATERIALS AND METHODS}

A retrospective study was performed at St. Paul's Hospital Millennium Medical College, in Addis Ababa, Ethiopia, from January to August 2018. St. Paul's Hospital Millennium Medical College is a teaching hospital for both undergraduate and postgraduate studies with 110 surgical beds. . All patients who had colorectal anastomosis from January 2013 to December 2017 GC were included in the study. Patients operated elsewhere and referred to SPHMMC, who had protective stoma, missed or incomplete charts were excluded from the study.

The operation theater log book was used to identify patients and individual patients medical records were reviewed to extract data. Data on patients' socio- demographic characteristics, clinical/lab parameters including co-morbidities , smoking habits, ASA score, hematocrit level, serum Albumin level, history of previous abdominal surgery, preoperative chemo radiation, intra-operative blood transfusion, indication for operation, urgency of operation, type of procedure, duration of operation, Anastomotic leak, surgical site infection, wound dehiscence, $\mathrm{ECF}$, re laparotomy were collected by trained surgical residents in a pretested data collection format. Data collection was supervised and quality of data checked every day.

The data was analyzed using SPSS version 23. Univariate analysis followed by a multivariate logistic regression model was used to determine the influence of patient factors and operative events on postoperative anastomotic leakage. Statistical test chi square at 0.05 level of significance was used. A written ethical clearance letter was given from SPHMMC's institutional review board. Data acquired was used only for the study and patients' information used in the research was kept confidential.

DOI: http://dx.doi.org/10.4314/ejhs.v29i6.14 
As this is a retrospective study, all the limitations of such type of study should be expected. Some of the patients lacked properly registered data and complete investigations. The non-response rate of the study was $17 \%$.

Anastomotic leakage was deemed to have occurred when there were: signs of peritonitis and/or purulent/ feculent discharge from a drain or wound and/or radiological evidence (a fluid collection in proximity to an anastomosis and/or operative evidence of anastomotic disruption. Malnutrition was defined by albumin $<3.5$ or total serum protein $<5.5$ or unintentional weight loss more than $10 \%$ body weight in the last 6 months.

Anemia was assumed to be present when hematocrit was less than $30 \%$ or hemoglobin less than $10 \mathrm{~g} / \mathrm{dl}$.

\section{RESULTS}

During the study 266 patients had colorectal anastomosis (CRA) without protective stoma. Of these, 20 patients with incomplete charts and 25 patients whose charts could not be retrieved were excluded. Hence analysis was based on the $221(83.1 \%)$ patients with complete record. The main form of surgeries were primary colon resection and anastomosis 226(85\%) and colostomy reversal $60(15 \%)$. Age of the patients ranged from 1 to 85 with mean age 46.44(IQR, 32-60). Majority $166(74.8 \%)$ of patients were male making the male to female ratio 3:1. Most surgeries were for benign conditions $177(80 \%)$ and on elective basis 181(81.9\%). Duration of procedure was less than three hours in $179(81.4 \%)$ of patient. Only 20 patients $(9.1 \%)$ required perioperative blood transfusion (Table 1).

Table 1. Patient population and results of Univariate Analysis of Patient Demographics, Preoperative risk factors for anastomosis leak, among patients with Colonic anastomosis at St. Paul Hospital Millennium Medical College, Addis Ababa, Ethiopia from January 2013 to December 2017 G.C.

\begin{tabular}{|c|c|c|c|c|c|}
\hline & & Total cases & $\begin{array}{l}\text { Anastomosis } \\
\text { leaked }\end{array}$ & $\begin{array}{l}\text { No } \\
\text { Anastomosis } \\
\text { leak }\end{array}$ & p-Value \\
\hline \multirow[t]{2}{*}{ Sex } & Male & $166(75.1)$ & $6(3.6)$ & $160(96.4)$ & 0.054 \\
\hline & Female & $55(24.9)$ & $6(10.9)$ & $49(89.1)$ & \\
\hline Age (Years) & Mean (SD) & $46.4(19.1)$ & $42.2(16.0)$ & $46.9(19.3)$ & 0.426 \\
\hline \multirow{2}{*}{$\begin{array}{l}\text { Urgency of } \\
\text { operation }\end{array}$} & Elective & 181(81.9) & $7(3.9)$ & $174(96.1)$ & 0.03 \\
\hline & Emergency & $40(18.1)$ & $5(12.5)$ & $35(87.5)$ & \\
\hline \multirow{4}{*}{$\begin{array}{l}\text { Nature of the } \\
\text { conditions } \\
\text { Types of } \\
\text { anastomosis }\end{array}$} & Malignant & $44(20)$ & $7(15.9)$ & $37(84.1)$ & 0.01 \\
\hline & Benign & $177(80)$ & $5(2.8)$ & $172(97.2)$ & \\
\hline & Primary & $165(74.7)$ & $11(6.7)$ & $154(93.3)$ & 0.164 \\
\hline & $\begin{array}{l}\text { Colostomy } \\
\text { reversal }\end{array}$ & $56(25.3)$ & $1(1.8)$ & $55(98.2)$ & \\
\hline \multirow{5}{*}{$\begin{array}{l}\text { Duration of } \\
\text { surgery } \\
\text { ASA score }\end{array}$} & $<3$ hours & 179(81.4) & $6(2.8)$ & $173(97.2)$ & 0.04 \\
\hline & $>3$ hours & $41(18.6)$ & $6(14.6)$ & $35(85.4)$ & \\
\hline & $\mathrm{I}, \mathrm{II}$ & $160(72.4)$ & $4(2.5)$ & $156(97.5)$ & 0.05 \\
\hline & III,IV & $5(2.3)$ & $1(20.0)$ & $4(80.0)$ & \\
\hline & Unknown & $56(25.3)$ & $7(12.5)$ & $49(87.5)$ & \\
\hline Preoperative & $>30 \%$ & $209(94.5)$ & $10(4.8)$ & 199 (95.2) & 0.057 \\
\hline \multirow[t]{2}{*}{ Hematocrite } & $<=$ less $30 \%$ & $11(5)$ & $2(18.2)$ & $9(81.9)$ & \\
\hline & Unknown & $1(0.5)$ & & & \\
\hline
\end{tabular}

DOI: http://dx.doi.org/10.4314/ejhs.v29i6.14 
Commonest indication for CRA was redundant cancers $44,(20 \%)$ (Table 2). sigmoid 125 (56.5\%) followed by Colon and rectal

Table 2. Conditions requiring anastomosis involving the colon or rectum at St. Paul Hospital Millennium Medical College, A.A, Ethiopia from January 2013 to December 2017 G.C

\begin{tabular}{lcl}
\hline Conditions & Number & Percent \\
\hline Colon and rectal cancers & 44 & 20 \\
Intussusception & 21 & 9.6 \\
Redundant sigmoid & 125 & 56.5 \\
IBD (Crhon's disease) & 5 & 2.2 \\
Intestinal Tuberculosis & 3 & 1.4 \\
Mesenteric ischemia & 4 & 1.8 \\
Traumatic injury & 9 & 4 \\
Others & 10 & 4.5 \\
Total & 221 & 100 \\
\hline
\end{tabular}

Incidence of anastomosis leak: Anastomotic leak was diagnosed in $12(5.2 \%)$ patients with mean time to diagnosis after the operation was 9.55 days (95\% CI, 7.2-11.8), median 10 days, and range 314 days. Mean age of patients with anastomosis leak was $42.16[\mathrm{SD}=15.97]$ compared to $46.68[\mathrm{SD}=19.25]$ in patients without leak, $(\mathrm{p}=0.46)$. Anastomotic leakage was found in $10.9 \%$ (6) of women versus $3.6 \%$ (6) of men,
$\mathrm{P}=0.054$ ). Incidence of $\mathrm{AL}$ after emergency operation was $12.5 \%$ compared to $3.9 \%$ in elective operation $(\mathrm{P}=0.029)$. Anastomotic leakage after malignant colorectal lesions was $15.9 \%$ versus $2.8 \%$ in benign condition, $(\mathrm{p}=.0 .01)$ (Table 1$)$. Highest incidence of $\mathrm{AL}$ occurred after right hemicolectomy $5(13.9 \%)$ followed by LAR $1(12.5 \%), \mathrm{P}=0.085$.

Table 3. Comorbidities and their association with colonic anastomosis leak among patients with Colonic anastomosis at St. Paul Hospital Millennium Medical College, Addis Ababa, Ethiopia from January 2013 to December 2017 G.C

\begin{tabular}{llllll}
\hline & Total cases & $\begin{array}{l}\text { Anastomosis } \\
\text { leaked }\end{array}$ & $\begin{array}{l}\text { No } \\
\text { Anastomosis } \\
\text { leak }\end{array}$ & p-Value \\
\hline $\begin{array}{l}\text { Previous } \\
\text { abdominal } \\
\text { surgery }\end{array}$ & Yes & $71(32.1)$ & $3(4.2)$ & $68(95.8)$ & 0.59 \\
DM & No & $150(67.9)$ & $9(6.0)$ & $141(94.0)$ & \\
& Yes & $4(1.8)$ & $1(25)$ & $3(75)$ & 0.081 \\
Cardiac disease & Ye & $217(98.2)$ & $11(5.1)$ & $206(94.9)$ & \\
& Yes & $10(4.5)$ & 0 & $10(100)$ & 0.438 \\
HTN & No & $211(95.5)$ & $12(5.7)$ & $199(94.3)$ & \\
& Yes & $19(8.6)$ & $1(5.3)$ & $18(94.7)$ & 0.973 \\
Creatinine & No & $202(91.4)$ & $11(5.4)$ & $191(94.6)$ & \multirow{2}{*}{0.02} \\
Level & Yes & $6(2.7)$ & $2(33.3)$ & $4(66.7)$ & \\
RVI & No & $215(97.3)$ & $10(4.7)$ & $205(95.3)$ & 0.147 \\
& Yes & $5(2.3)$ & $1(20)$ & $4(80)$ & \\
\hline
\end{tabular}

DOI: http://dx.doi.org/10.4314/ejhs.v29i6.14 
Risk Factors: Demographic characteristics, comorbidities, and procedural characteristics were tested for associations with AL. Five risk factors were associated with AL in univariate analyses (high preoperative level of creatinine $(\mathrm{p}=0.02)$, ASA score III and IV $(\mathrm{p}=0.05)$, emergency operation $(\mathrm{P}=0.03)$, operative time more than three hours $(\mathrm{p}=0.04)$, and malignant pathology $(\mathrm{p}=0.01))($ Table 1 and 2). All of these variables were entered into multivariate logistic regression and none of the variables had statistically significant association with AL. There was no significant statistical association between $\mathrm{AL}$ and age, preoperative hematocrit and albumin,

preoperative transfusion, DM, cardiac disease, HTN and RVI.

Morbidity and Mortality: A total of 47 (21.3\%) complications occurred and 16 patients died. Only two patients with AL survived (Table 5). In patients with $\mathrm{AL}$, inpatient mortality rate increased to $50 \%(6 / 12)$ but it was $4.8 \%(10 / 209)$ in patients without AL, $(\mathrm{P}<0.001)$. The median postoperative length of hospitalization was 8 days (25॰-75॰ percentile, 6-12 days) for the whole group. In patients with $\mathrm{AL}$ the median length of hospitalization was 27.5 days $\left(25^{\circ}-75^{\circ}\right.$ percentile, 9-19 days) compared to 7 days $\left(25^{\circ}-75^{\circ}\right.$ percentile, 6-9 days) in patients without AL, $\mathrm{p}=.0 .01$

Table: -4 Type of resections and univariate analysis, among patients with Colonic anastomosis at St. Paul Hospital Millennium Medical College, A.A, Ethiopia from January 2013 to December 2017.

\begin{tabular}{lcccc}
\hline \multicolumn{1}{c}{ Type of resection } & No.(\%) & $\begin{array}{c}\text { Anastomosis } \\
\text { Leak, No.(\%) }\end{array}$ & $\begin{array}{c}\text { No Anastomosis Leak, } \\
\text { No.(\%) }\end{array}$ & P value, CI \\
\hline Ileocecal resection & $14(6.3)$ & $1(7.1)$ & $13(92.9)$ & 0.085, CI=1.77_2.08 \\
$\begin{array}{l}\text { Right } \\
\text { hemicolectomy }\end{array}$ & $36(16.2)$ & $5(13.9)$ & $31(86.1)$ & CI=1.74_1.98 \\
Transverse & $1(0.5)$ & 0 & $1(100)$ & \\
colectomy & & & & \\
Left hemicolectomy & $5(2.3)$ & 0 & $5(100)$ & \\
Sigmoid colectomy & $93(41.9)$ & 0 & $93(100)$ & 0.06 \\
$\quad$ LAR & $8(3.6)$ & $1(12.5)$ & $7(87.5)$ & \\
Subtotal colectomy & $1(0.5)$ & $1(100)$ & 0 & \\
Total colectomy & $2(0.9)$ & 0 & $2(100)$ & \\
Colostomy reversal & $57(25.8)$ & $1(1.8)$ & $56(98.2)$ & \\
Others & $4(1.8)$ & $3(75)$ & $1(25)$ & \\
\hline
\end{tabular}

Table:-5 Clinical outcome after AL, among patients with Colonic anastomosis at St. Paul Hospital Millennium Medical College, A.A, Ethiopia from January 2013 to December 2017 G.C

\begin{tabular}{llccc}
\hline & Total & $\begin{array}{c}\text { Anastomosis leak } \\
\mathbf{N = 1 2}\end{array}$ & $\begin{array}{c}\text { No Anastomosis } \\
\text { leak N=209 }\end{array}$ & P value \\
\hline $\begin{array}{l}\text { Superficial Surgical Site } \\
\text { Infection }\end{array}$ & $\mathbf{2 6 ( 1 2 . 7 )}$ & $4(33.3)$ & $22(13.4)$ & 0.027 \\
Wound dehiscence & $\mathbf{1 0}(\mathbf{4 . 5 )}$ & $4(33.3)$ & $6(2.8)$ & $<0.001$ \\
Intra-abdominal abscess & $\mathbf{5 ( 2 . 7 )}$ & $4(33.3)$ & $1(0.48)$ & $<0.001$ \\
ECF & $\mathbf{6 ( 2 . 7 )}$ & $5(41.6)$ & $1(0.48)$ & $<0.001$ \\
Re-laparotomy & $\mathbf{1 0 ( 4 . 5 )}$ & $5(41.6)$ & $5(2.4)$ & $<0.001$ \\
Mean(SD) Length of hospital & $9.28(6.9)$ & $26.25(3.67)$ & $8.33(0.346)$ & $<0.001$ \\
stay(days) & & & $6(50 \%)$ & $<0.001$ \\
Inpatient death & $16(7.2 \%)$ & $10(4.8)$ & & \\
\hline
\end{tabular}

DOI: http://dx.doi.org/10.4314/ejhs.v29i6.14 


\section{DISCUSSION}

In this 5 years retrospective study, among 221 patients meeting inclusion criteria, anastomotic leak was diagnosed in $12(5.2 \%)$ patients and median time to AL was 10 days (IQR 7.5-8 days) ranging between 3-14 days. This anastomotic leak rate is well within expectation based on recent literatures where leak rate ranges between $4.9 \%$ and $7.2 \% \quad(12,16)$. Multivariate Prospective, National Study done in Valencia, Spain with 3193 Patients by Matteo Frasson et al (13), CAL was diagnosed in 277 patients $(8.7 \%)$ between postoperative days 1 and 52 (median of 6 days, $25^{\circ}-75^{\circ}$ percentile $4-10$ days)

In our study's univariate assessment of age as a risk factor for CAL does not show significant association which is consistent with studies by Boccola MA et al (14) and Kang CY et al. (15). Prospective observational meta analyses done in Denmark (16) to evaluate age as a risk factor failed to show significant association with CAL. The fact that age in itself in otherwise healthy and fit patients does not seem to be a contraindication for primary anastomosis is interesting. Increased age may increase the risk for comorbidity, but still many elderly patients may be perfectly healthy. Reported predictors for anastomotic leakage such as previous abdominal surgery, diabetes mellitus, cardiovascular disease, male gender could not be confirmed in our present analysis. Similar to our findings, a prospective study done by Dana A. Telem, MD et al. (17) demonstrated no increased risk for CAL by sex, preoperative diagnosis of cardiovascular disease and Diabetes Mellitus. But other studies conducted by C Iancu et al. (22) and Andrea Vignali et al. (23) showed that diabetes mellitus and cardiovascular diseases were significantly related to the occurrence of anastomotic leak.

American Society of Anesthesiologists score remained a significant predictor of anastomosis leak in our study, it was associated with anastomotic leakage in univariate analyses. Patients with a high ASA-class may be more prone to CAL owing to an increased comorbidity rate (e.g. cardiovascular or pulmonary diseases), which may impair tissue perfusion and oxygenation.
A high preoperative level of creatinine was associated with $\mathrm{AL}$ in the univariable model but did not quite reach significance in the multivariable model which is similar to finding of Mikkel Jessen, Malene Nerstrøm, et al. (12) in Berlin , Germany, . Here, a high creatinine level was associated with a high ASA score and thus a proxy of overall comorbidity.

Surgery related factors such as emergency operation and operation time more than three hours remained significant predictor of anastomotic leak in univariate analyses in our study but multivariate analysis failed to show significant association. Emergency surgery, which intuitively should put patients at a higher risk for adverse postoperative events, was indeed reported to be associated with AL based on univariate and multivariate analysis by N. Koimen et al. (18) but this association was not consistently found by others $(19,20)$. In our study, emergency surgery was also associated with AL based on univariate analysis $(\mathrm{P}=0.029)$, but did not remain significant after multivariate logistic regression analysis. Only $18.1 \%(\mathrm{n}=40)$ of patients in our study population underwent this operation emergently, and only $12.5 \%(\mathrm{n}=5)$ of all anastomotic leaks were found among emergent cases, thus limiting the statistical power of this assessment in our analysis. This finding is similar with study done by Stefan W. Leichtle, etal. (21)

In our study overall inpatient mortality was $16 / 221(7.2 \%)$ and $11 / 221(3.4 \%)$ in elective patients compared with 14/105 (7.2 \%) in emergency patients, $\mathrm{P}<0.001$. As can be expected it was higher in emergency patients. The mortality rate in patients with $\mathrm{AL}$ was $6 / 12(50 \%)$ compared with $10 / 109(9.2 \%)$ in patients without AL, P $<0.001$ which is statically significant. As patients with AL will develop fecal peritonitis in a compromised physiology and anatomy mortality rate is expected to be high as seen in our case.

This is much higher than most recent literatures which is between $10 \%$ to $20 \%$ (5). Retrospective study done by Komen, et al. (18) on 739 patients mortality rate due to leakage was $14.1 \%$. The mortality rate among patients with $\mathrm{AL}$ was significantly higher than in those without leakage $(16 \cdot 4$ versus $3 \cdot 1$ per cent; $\mathrm{P}<0 \cdot 001)$

DOI: http://dx.doi.org/10.4314/ejhs.v29i6.14 
In conclusion $\mathrm{AL}$ remains an important postoperative complication among patients who had colorectal anastomosis. The presence of renal disease, ASA score of III and IV, emergency operation, operative time more than three hours, and malignant pathology were associated with $\mathrm{AL}$ in univariate analyses. Multivariate analysis controlling for multiple confounding factors demonstrated that no patient-related or surgeryrelated factors were associated with AL. However, further studies are needed which focus on risk factors that currently are insufficiently explored. AL has significantly increased the inpatient mortality rate and post-operative stay of patients with significant statistical association. There was a delay in detecting CAL which increases the mortality rate. High index of suspicion and timely intervention can improve patient outcomes.

The limitations of this study are the retrospective nature of the study, some of the patients lacked properly registered data and a non-response rate of $17 \%$.

\section{ACKNOWLEDGMENTS}

We would like to thank St. Paul's Hospital Millennium Medical College for providing us the necessary materials and fund.

\section{REFERENCES}

1. Vallance A, Wexner S, Berho $\mathrm{M}$ et al. A collaborative review of the current concepts and challenges of anastomotic leaks in colorectal surgery. Colorectal Disease. 2017 Jan;19(1):O1-2.

2. Rahbari NN, Weitz J, Hohenberger W et al. Definition and grading of anastomotic leakage following anterior resection of the rectum: a proposal by the International Study Group of Rectal Cancer. Surgery. 2010 Mar 1;147(3):339-51.

3. Telem DA, Chin EH, Nguyen SQ, Divino CM. Risk factors for anastomotic leak following colorectal surgery: a case-control study. Archives of surgery. 2010 Apr 1;145(4):371-6
4. Komen NN. New approaches towards risk assessment, diagnosis and prevention strategies of colorectal anastomotic leakage.

5. Daams F, Luyer M, Lange JF. Colorectal anastomotic leakage: aspects of prevention, detection and treatment. World Journal of Gastroenterology: WJG. 2013 Apr 21;19(15):2293.

6. Bielecki K, Gajda A. The causes and prevention of anastomotic leak after colorectal surgery. Klin Onkol. 1999;12(Suppl 1999):2530.

7. Lipska MA, Bissett IP, Parry BR, Merrie AE. Anastomotic leakage after lower gastrointestinal anastomosis: men are at a higher risk. ANZ journal of surgery. 2006 Jul;76(7):579-85.

8. Bodil Gessler. Diagnosis, treatment and consequence of anastomotic leakage in colorectal surgery. International Journal of colorectal disease 2017 32:549_556

9. Schrock TR, Deveney CW, Dunphy JE. Factor contributing to leakage of colonic anastomoses. Annals of surgery. 1973 May;177(5):513.

10. Boccola MA, Lin J, Rozen WM, Ho YH. Reducing anastomotic leakage in oncologic colorectal surgery: an evidence-based review. Anticancer Research. 2010 Feb 1;30(2):601-7.

11. Hammond J, Lim S, Wan Y, Gao X, Patkar A. The burden of gastrointestinal anastomotic leaks: an evaluation of clinical and economic outcomes. Journal of Gastrointestinal Surgery. 2014 Jun 1;18(6):1176-85.

12. Jessen M, Nerstrøm M, Wilbek TE, Roepstorff S, Rasmussen MS, Krarup PM. Risk factors for clinical anastomotic leakage after right hemicolectomy. International journal of colorectal disease. 2016 Sep 1;31(9):1619-24.

13. Frasson M, Flor-Lorente B, Rodríguez JL et al. Risk factors for anastomotic leak after colon resection for cancer. Annals of surgery. 2015 Aug 1;262(2):321-30.

14. Boccola MA, Buettner PG, Rozen WM et al. Risk factors and outcomes for anastomotic leakage in colorectal surgery: a single- 
institution analysis of 1576 patients. World journal of surgery. 2011 Jan 1;35(1):186-95.

15. Kang CY, Halabi WJ, Chaudhry OO et al. Risk factors for anastomotic leakage after anterior resection for rectal cancer. JAMA surgery. 2013 Jan 1;148(1):65-71.

16. Abraham NS, Young JM, Solomon MJ. Meta-analysis of short-term outcomes after laparoscopic resection for colorectal cancer. British journal of surgery. 2004 Sep;91(9):1111-24.

17. Telem DA, Chin EH, Nguyen SQ, Divino CM. Risk factors for anastomotic leak following colorectal surgery: a case-control study. Archives of surgery. 2010 Apr 1;145(4):371-6.

18. Slieker JC, Komen NA, Mannaerts GH et al. Long-term and peri-operative corticosteroids in anastomotic leakage: a prospective study among 259 left-sided colorectal anastomoses. Improving Quality in Colorectal Surgery. 2014;147(5):113.

19. Buchs NC, Gervaz P, Secic M, Bucher P, Mugnier-Konrad B, Morel P. Incidence, consequences, and risk factors for anastomotic dehiscence after colorectal surgery: a prospective monocentric study. International journal of colorectal disease. 2008 Mar 1;23(3):265-70.

20. Lipska MA, Bissett IP, Parry BR, Merrie AE. Anastomotic leakage after lower gastrointestinal anastomosis: men are at a higher risk. ANZ journal of surgery. 2006 Jul;76(7):579-85.

21. Leichtle SW, Mouawad NJ, Welch KB, Lampman RM, Cleary RK. Risk factors for anastomotic leakage after colectomy. Diseases of the Colon \& Rectum. 2012 May 1;55(5):569-75.

22. Iancu C, Mocan LC, Todea-Iancu D et al. Host-related predictive factors for anastomotic leakage following large bowel resections for colorectal cancer. J Gastrointestin Liver Dis. 2008 Sep 1;17(3):299-303.

23. Vignali A, Fazio VW, Lavery IC et al. Factors associated with the occurrence of leaks in stapled rectal anastomoses: a review of 1,014 patients. Journal of the American College of Surgeons. 1997 Aug 1;185(2):105-13. 